\title{
Occurrence of haemoparasites in cattle in Monduli district, northern Tanzania
}

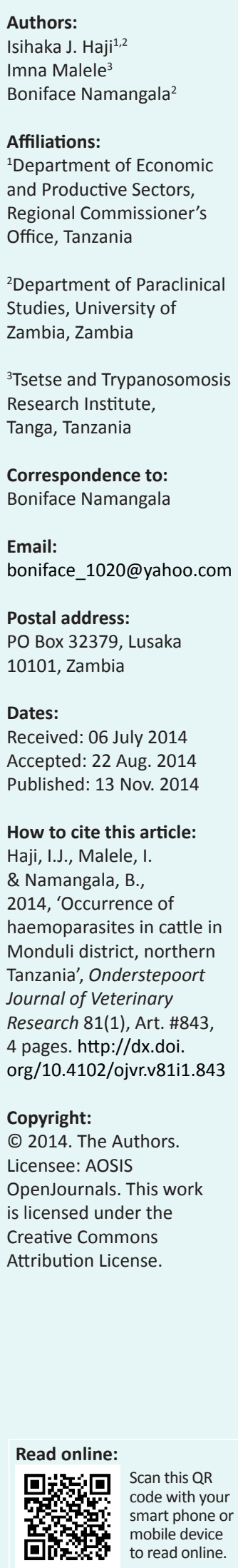

Haemoparasite infections are among the most economically important cattle diseases in sub-Saharan Africa. The present study investigated the occurrence of haemoparasites in 295 indigenous cattle from five villages (Mswakini, Lake Manyara, Naitolia, Makuyuni and Nanja) of the Monduli district, a wildlife-domestic animal-human interface area in northern Tanzania. The data showed that the overall occurrence of haemoparasites in the sampled cattle was $12.5 \%$ (95\% CI: 8.7\% - 16.3\%), involving single and mixed infections with Theileria parva, Anaplasma marginale, Babesia bovis, Trypanosoma vivax and Trypanosoma brucei. The highest haemoparasite occurrence was recorded in Lake Manyara (18.3\%; 95\% CI: $8.5 \%-28.1 \%$ ), and the lowest was recorded in Nanja (6.5\%; 95\% CI: $0.4 \%-12.6 \%)$. This preliminary study, furthermore, provided evidence of the possible arthropod vectors (ticks and tsetse flies) that may be involved in the transmission of haemoparasites to cattle in the Monduli district. It is envisaged that this survey will stimulate more studies to determine the prevalence of haemoparasites in livestock by using more sensitive molecular techniques.

\section{Communication}

In sub-Saharan Africa, ticks are the most important ectoparasites involved in the transmission of numerous haemoparasite infections such as theileriosis, babesiosis, anaplasmosis and rickettsiosis (Gitau et al. 1997; Makala et al. 2003; Swai et al. 2007). In addition, the haematophagous ticks that contribute to cattle anaemia cause physical damage to the hide and the resultant wounds make the animals susceptible to myiasis (Snelson 1995). Tsetse flies are the second most important vectors; they are mainly involved in the transmission of bovine trypanosomosis (Laohasinnarong et al. 2011). Such haemoparasite infections are also an impediment to the introduction of more productive exotic cattle breeds (Makala et al. 2003). The Zebu cattle (Bos indicus) are more resistant than the exotic breeds (Bos taurus) against both the haemoparasites and the arthropod vector (Jongejan et al. 1988). Although haemoparasites may be more accurately diagnosed by the more sensitive molecular techniques such as polymerase chain reaction (PCR) and loop-mediated isothermal amplification (LAMP) or by serology, microscopy remains the most reliable, available and affordable test in the resource-imited endemic areas such as Tanzania (Mitashi et al. 2012).

A cross-sectional survey was conducted from November to December 2013 in the Monduli district $\left(3^{\circ} 20^{\prime} \mathrm{S}, 36^{\circ} 15^{\prime} \mathrm{E}\right)$, which is an important wildlife-domestic animal-human interface area located in northern Tanzania, to investigate the occurrence of haemoparasites in the indigenous Tanzanian short horn zebu (TSHZ) and Boran crosses. A total of 295 cattle, comprising 255 TSHZ and 40 Boran crosses, were sampled from five villages (Mswakini, Lake Manyara, Naitolia, Makuyuni and Nanja) of the Monduli district, of which 203 (68.8\%) were female and 92 (31.2\%) were male. With regard to age: 41 (13.9\%) were under 12 months, 231 (78.3\%) were between 12 and 36 months, whilst $23(7.8 \%)$ were older than 36 months. After clinical examination and body condition scoring, as described by Munang'andu et al. (2010), blood was collected from the jugular vein into labelled, heparinised tubes. During the sampling exercise, data for animal identification and clinical history of individual cattle were captured on a form. The packed cell volume (PCV) values were determined and Giemsa-stained thin blood smears from each animal were examined by microscopy; the blood parasites were identified as previously described (Almeria et al. 2001; Soulsby 1982).

Data ( \pm standard error [s.e.]) captured on record sheets were entered, stored and statistically analysed using SPSS version 16.0. Mean PCV in infected and non-infected cattle were compared using the one-way analysis of variance. All statistical tests were considered significant at $p<0.05$.

Clinical examination revealed that 29 (9.8\%) cattle were infested with various species of ticks, including Amblyomma, Hyalomma, Rhipicephalus and Boophilus species (Horak 2009) and that 35 
(11.9\%) animals were emaciated. A few tsetse flies (Glossina pallidipes and Glossina swinnertoni) (Krinsky 2009) were also seen at some sampling sites.

Of the 295 cattle sampled, 37 (12.5\%; 95\% CI: 8.7\% - 16.3\%) had haemoparasite infections. Table 1 summarises the occurrence of single and/or mixed infections with Theileria parva, Babesia bovis, Anaplasma marginale, Trypanosoma vivax and Trypanosoma brucei in the sampled Monduli cattle. The highest haemoparasite infection was recorded from Lake Manyara village (18.3\%; 95\% CI: $8.5 \%-28.1 \%)$, whilst the lowest was from Nanja village $(6.5 \%$; $95 \%$ CI: $0.4 \%-12.6 \%)$ (Table 1); however, there was no statistically significant difference $(p=0.12)$ in the occurrence of bovine haemoparasite infection observed among villages. The average ages for infected and non-infected cattle were 20.3 months and 18.3 months, respectively. Although a tendency towards lower PCV values was observed in infected animals from some villages, in general, there was no significant difference ( $p=0.08)$ in the mean PCVs of cattle that were detected with haemoparasites $(29.2 \% \pm 1.7)$ and the animals in which they were not detected $(31.2 \% \pm 0.3)$.

In the present survey, the occurrence of haemoparasite infection in the indigenous TSHZ and Boran crosses reared communally in Monduli district in northern Tanzania was determined by microscopy. Considering the fact that microscopy may fail to detect haemoparasites in cattle with low parasitaemia, it is possible that the rate of bovine haemoparasite infection would be higher if more sensitive molecular techniques were used (Namangala et al. 2012; Thekisoe et al. 2007). However, despite its limitations in terms of sensitivity and specificity, microscopy remains the most commonly used definitive diagnostic test of haemoparasite infections in resource-poor countries such as Tanzania (Laohasinnarong et al. 2011) as it is simple, reliable and inexpensive (Mitashi et al. 2012). It is still one of the most widely used diagnostic tests in the field and can simultaneously demonstrate several haemoparasite species, as was the case in the present study.

Most of the haemoparasite-infected cattle did not manifest clinical disease, apart from poor body condition and anaemia, which could have been due to multiple causes including worm and tick infestation as well as poor pasture during the sampling period. Although approximately $12.0 \%$ of the cattle were emaciated, only a few emaciated animals tested positive for haemoparasites. Moreover, there was no significant difference in the PCV values of infected and non-infected cattle. These data support the notion that the indigenous Monduli TSHZ and Boran crosses may be relatively tolerant to haemoparasite infections (Taylor 1998). Normally, such haemoparasite-infected cattle would be expected to show more severe clinical signs, considering the fact that (1) they generally had a poor body condition score and (2) most of them rarely received veterinary services, hence the observed tick burden, which could have contributed to anaemia. Nonetheless, the majority of those cattle were either asymptomatic or only exhibited mild signs, with no case of acute infection. Therefore, in addition to possible indirect effects on productivity, such cattle could act as a source of theileriosis, trypanosomosis, anaplasmosis and babesiosis (Laohasinnarong et al. 2011; Makala et al. 2003; Swai et al. 2007) for other susceptible livestock, particularly the more productive exotic animals. It is also noteworthy that such haemoparasite-infected, asymptomatic cattle may serve as reservoirs of the zoonotic Trypanosoma brucei rhodesiense and Trypanosoma brucei gambiense, which may cause sleeping sickness (Welburn et al. 2001).

Although Trypanosoma congolense is one of the common causes of trypanosomosis in cattle, it was not detected in the present study. In agreement with Swai and Kaaya (2012), a relatively higher occurrence of $T$. vivax in cattle blood sampled can be reported. This may be as a result of reduced presence of the biological tsetse vectors for $T$. congolense and increased presence of other haematophagous arthropods, including insect vectors such as Tabanus, Stomoxy and Haematopota species that could easily transmit $T$. vivax mechanically.

According to data obtained in the present study, the occurrence of bovine haemoparasites seems to be associated with proximity to national parks. Although not statistically significant, a tendency was observed towards higher occurrences of haemoparasites in cattle from Lake Manyara ( $18 \%)$ and Naitolia ( 14\%) villages, which are close to Lake Manyara National Park with abundant arthropod vectors and wild animal reservoirs of haemoparasites (Munag'andu et al. 2010), compared to Nanja village (6\%), which is located much further from Lake Manyara National Park and close to Monduli town, with better access to veterinary services. Furthermore, the occurrence of bovine haemoparasite infection appears to be linked with age, with calves tending to have a lower infection rate than adults. This may be partially explained by the fact that calves usually graze close to home, as compared to older animals that graze far into the bush, with increased frequency of being bitten by infected arthropod vectors (Bett et al. 2004; Lisulo et al. 2014).

\section{Ethical considerations}

Blood samples were obtained from cattle whose owners agreed to the sampling after giving their informed consent to participate in the survey.

\section{Conclusion}

The present study has provided evidence of both the haemoparasites and, potentially, their arthropod vectors (ticks and tsetse flies) responsible for disease transmission to the indigenous Tanzanian cattle in Monduli district. It is, therefore, envisaged that this survey will stimulate more studies to determine the prevalence of haemoparasites in Tanzanian livestock using more sensitive molecular techniques such as PCR and/or LAMP. The regular use of insecticides to control the arthropod vectors of haemoparasites in Monduli district is highly recommended. 


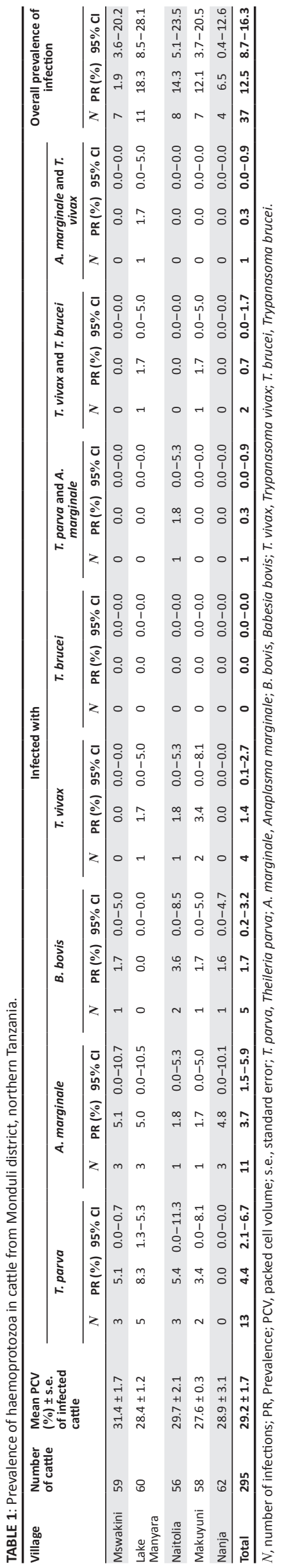

\section{Acknowledgements}

This study received financial support from the Southern Africa Centre for Infectious Disease Surveillance (SACIDS). The authors would also like to thank the Monduli farmers, the Assistant Administrative Secretary Arusha Regional Secretariat, the Department of Livestock and Fisheries in Monduli district council and the technical staff at Tanzania veterinary laboratory agency (TVLA) Arusha centre for their assistance and support. The authors declare that there is no conflict of interest.

\section{Competing interests}

The authors declare that they have no financial or personal relationships that may have inappropriately influenced them in writing this article

\section{Authors' contributions}

I.J.H. (Regional Commissioner's Office) helped to conceive the study, participated in its design, obtained funding, collected samples, performed microscopy, analysed data and drafted the manuscript. I.M. (Tsetse and Trypanosomosis Research Institute) co-supervised the study, participated in its design and helped in editing the manuscript. B.N. (University of Zambia) supervised and helped to conceive the study, participated in its design and edited the manuscript.

\section{References}

Almeria, S., Castellà, J., Ferrer, D., Ortuño, A., Estrada-Peña, A. \& Gutiérrez, J.F. 2001, 'Bovine piroplasms in Minorca (Balearic Islands, Spain): A comparison of PCR-based and light microscopy detection', Veterinary Parasitology 99, 249-259. http://dx.doi.org/10.1016/S0304-4017(01)00464-2

Bett, B., Orenge, C., Irungu, P. \& Munga, L.K., 2004, 'Epidemiological factors that influence time-to-treatment of trypanosomosis in Orma Boran cattle raised at Galana Ranch, Kenya', Veterinary Parasitology 120, 43-53. http://dx.doi. org/10.1016/j.vetpar.2003.12.011

Gitau, G.K., Perry, B.D., Katende, J.M., McDermott, J.J., Morzaria, S.P. \& Young, A.S. 1997, 'The prevalence of serum antibodies to tick-borne infections in cattle in smallholder dairy farms in Murang'a District, Kenya: A cross-sectional study', Preventive Veterinary Medicine 30, 95-107. http://dx.doi.org/10.1016/S01675877(96)01100-2

Horak, I.G., 2009, 'A century of tick taxonomy in South Africa', Onderstepoort Journal of Veterinary Research 76, 69-74. http://dx.doi.org/10.4102/ojvr.v76i1.67

Jongejan, F., Perry, B.D., Moorhouse, P.D., Musisi, F.L., Pegram, R.G. \& Snacken, M., 1988, 'Epidemiology of bovine babesiosis and anaplasmosis in Zambia' Tropical Animal Health and Production 20, 234-242. http://dx.doi.org/10.1007/ BF02239989

Krinsky, W., 2009, 'Tsetse-flies (Glossinidae)', in G.R. Mullen \& L.A. Durden (eds.), Medical and Veterinary Entomology, pp. 289-293. Academic Press, Oxford.

Laohasinnarong, D., Thekisoe, O.M., Malele, I., Namangala, B., Ishii, A., Goto, Y. et al., 2011, 'Prevalence of Trypanosoma sp. in cattle from Tanzania estimated by conventional PCR and loop-mediated isothermal amplification (LAMP)',
Parasitology Research 109, 1735-1739. http://dx.doi.org/10.1007/s00436011-2513-2

Lisulo, M., Sugimoto, C., Kajino, K., Hayashida, K., Mudenda, M., Moonga, L. et al., 2014, 'Determination of the prevalence of African trypanosome species in indigenous dogs of Mambwe district, eastern Zambia, by loop mediated isothermal amplification', Parasites and Vectors 7, 19-25. http://dx.doi org/10.1186/1756-3305-7-19

Makala, L.H., Mangani, P., Fujisaki, K. \& Nagasawa, H., 2003, 'The current status of major tick borne diseases in Zambia', Veterinary Research 34, 27-45. http:// dx.doi.org/10.1051/vetres:2002056

Mitashi, P., Hasker, E., Lejon, V., Kande, V. \& Muyembe, J.J., 2012, ‘Human African trypanosomiasis diagnosis in first - line health services of endemic countries, a systematic review', PLoS Neglected Tropical Diseases 6, e1919, viewed 06 July 2014, from http://www.plosntds.org/article/info\%3Adoi\%2F10.1371\%2Fjournal.
pntd.0001919

Munang andu, H.M., Siamudaala, V., Munyeme, M., Nambota, A., Mutoloki, S. \& Matandiko, W., 2010, 'Trypanosoma brucei infection in asymptomatic Greater Kudus (Tragelaphus strepsiceros) on a game ranch in Zambia', Korean Journal of Parasitology 48, 67-69. http://dx.doi.org/10.3347/kjp.2010.48.1.67

Namangala, B., Hachaambwa, L., Kajino, K., Mweene, A.S., Hayashida, K., Simuunza, M. et al., 2012, 'The use of loop-mediated isothermal amplification (LAMP to detect the re-emerging human African trypanosomiasis (HAT) in the Luangwa and Zambezi valleys', Parasites and Vectors 5, 282-286. http://dx.doi. 
Snelson, T.T., 1975, 'Animal ectoparasites and disease vectors causing major reductions in the world food supplies', FAO Plant Protection Bulletin 13, 103-114.

Soulsby, E., 1982, Helminths, Arthropods and Protozoa of Domestic Animals, Baillière, Tindall \& Cassell, London.

Swai, E.S. \& Kaaya, J.E., 2012, 'A parasitological survey for bovine trypanosomosis in the livestock/wildlife ecozone of Northern Tanzania', Veterinary World 5, 4592012.459-464

Swai, E.S., Karimuribo, E.D., Kambarage, D.M., Moshy, W.E. \& Mbise, A.N., 2007, 'A comparison of seroprevalence and risk factors for Theileria parva and '. mutan Journal 174, 390-396. http://dx.doi.org/10.1016/j.tvjl.2006.08.004
Taylor, K.A., 1998, 'Immune responses of cattle to African trypanosomes: Protective or pathogenic?', International Journal of Parasitology 28, 219-240. http://dx.doi. org/10.1016/S0020-7519(97)00154-9

Thekisoe, O.M., Kuboki, N., Nambota, A., Fujisaki, K., Sugimoto, C., Igarashi, I. et al., 2007, 'Species-specific loop-mediated isothermal amplification (LAMP) for diagnosis of trypanosomosis', Acta Tropica 102, 182-189. http://dx.doi. org/10.1016/j.actatropica.2007.05.004

Welburn, S.C., Picozzi, K., Fèvre, E.M., Coleman, P.G., Odiit, M., Carrington, M. et al., 2001 , 'Identification of human-infective trypanosomes in animal reservoir of sleeping sickness in Uganda by means of serum-resistance-associated (SRA) gene', Lancet 358, 2017-2019. http://dx.doi.org/10.1016/S0140-6736(01)07096-9 